Vol 9, No 1 (2021) | ISSN 2153-5914 (online) | DOI 10.5195/contemp/2021.325

http://contemporaneity.pitt.edu

\title{
Address the Issue
}

\author{
Joel Addison Fuller \& Seth Adam Cook
}

\begin{abstract}
About the Authors
Address the Issue, also known by the initialism A.I., is an American creative duo consisting of artists and activists Seth Cook and Joel Fuller. They first met while pursuing their master's degree in Fine Arts at Indiana University, Bloomington, in 2017, and started their collaboration in 2019. Their work addresses moments of racially motivated conflict in America that people too often would prefer to dismiss or forget. With each passing month, 2020 has brought awareness to the enduring division between black and white Americans. Now, A.I. see their collaboration as a way of highlighting polarizing perspectives that are further dividing the country, which cannot be recognized or empathized by the use of a stand-alone image. The global pandemic has made them more motivated to push the issues, going deeper into subject matter that some would consider controversial.
\end{abstract}

Joel Addison Fuller (b. 1993) is an artist born and raised in Birmingham, Alabama, a city known for its history of degradation and dehumanization of black people during the Civil Rights Movement. He is the nephew of Audrey Faye Hendricks, the youngest child arrested in the Civil Rights Movement, at the age of eight years old. His family not only participated in the movement, but also risked their bodies, economic security, and lives fighting for equal rights. While his aunt is no longer here, he honors her memory and legacy, being told to "never let our struggle fade into history." He holds a Bachelor of Fine Arts degree in art and design from Butler University. Shortly after receiving his bachelor's, he became a visual arts teacher for the Birmingham City School. He holds an MFA in digital art from Indiana University, Bloomington, with a focus on virtual reality and the Civil Rights Movement. His work has been displayed nationally, including Kentucky, South Carolina, Alabama, and Indiana.

Seth Adam Cook (b. 1993) is an artist born and raised in the Bayou Teche region of southcentral Louisiana, an area known for the community's connectedness to the land. After experiencing the aftermath of Hurricane Katrina and the poisoning of the Gulf Coast caused by 
the BP Oil Spill, he became motivated to confront the injustices that befell his community and ecosystem. He completed his Bachelor of Fine Arts from the University of Louisiana at Lafayette in 2015, and holds an MFA in photography from Indiana University, Bloomington. In 2018, while earning his master's, he gained recognition as a HASTAC scholar (Humanities, Arts, Science, and Technology Alliance and Collaboratory) for his experimentation with laser-cutting technology, the results of which were presented at the Institute for Digital Arts and Humanities 2019 Spring Symposium. His work has been displayed nationally, including Louisiana, New York, California, Colorado, Massachusetts, and Indiana. 


\section{Address the Issue}

\author{
Joel Addison Fuller \& Seth Adam Cook
}

In America, there is "White Innocence"-an innocence that serves as a quiet affirmation of the continuing racial paradigm against black Americans. First used by Gloria Wekker from her book White Innocence: Paradoxes of Colonialism and Race, the term refers to her Dutch ancestry, where the same issues of racial denial were-and remain-present. We look to use this term when connecting the systematic rejection of white Americans toward racial discrimination and the adverse effects of silence. In this series, we take inspiration from William Pope L. by using satire not simply to examine the stereotypes surrounding race but to dissect the damage these preconceptions do to both black and white individuals and, more broadly, to society. This includes but is not limited to the continued use of blackface, black cultural appropriation, and black people being seen as commodities of entertainment, objects of obsession, and subjects of fear. It is in this recognition that we understand the racial divide still taking place in what we were raised to believe was a "post-racial" America.
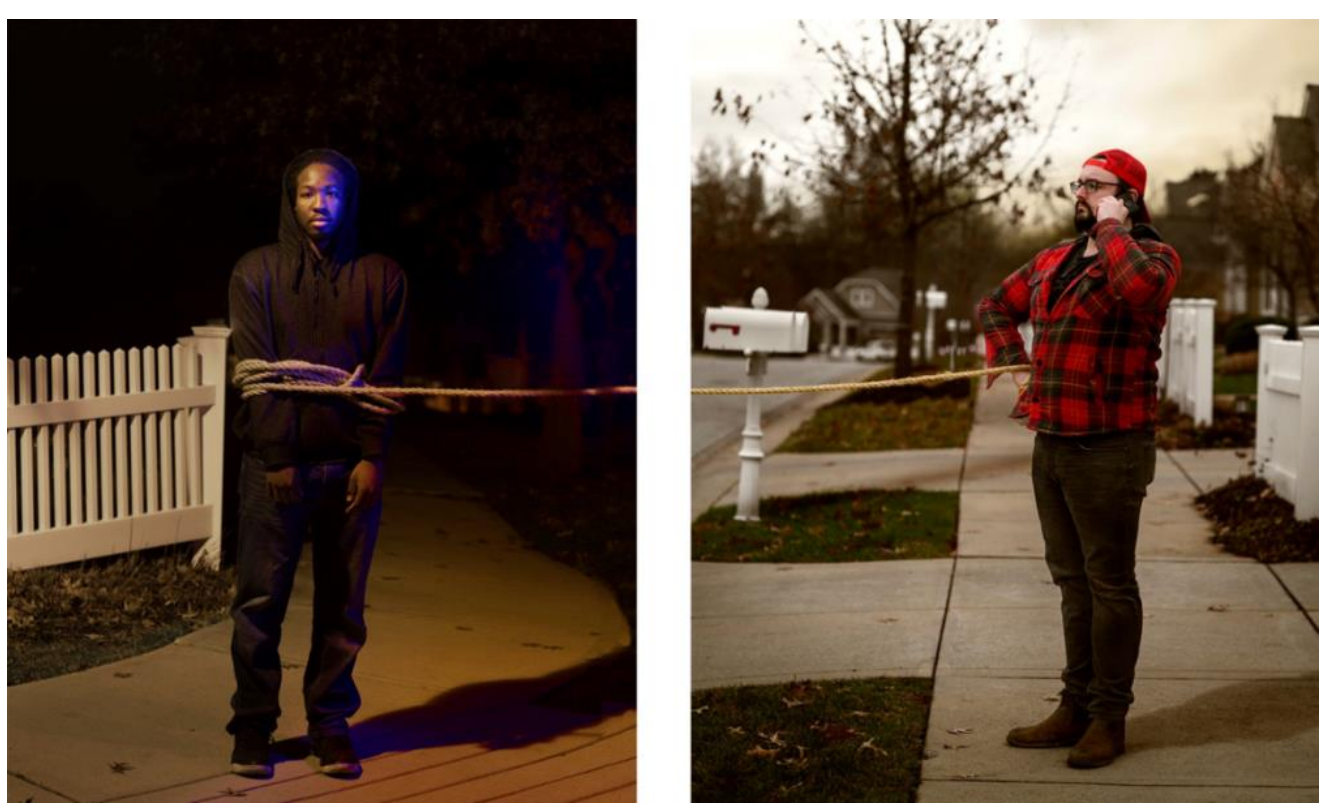

Figure 1

Address the Issue, I am Afraid, 2019. Photograph. 

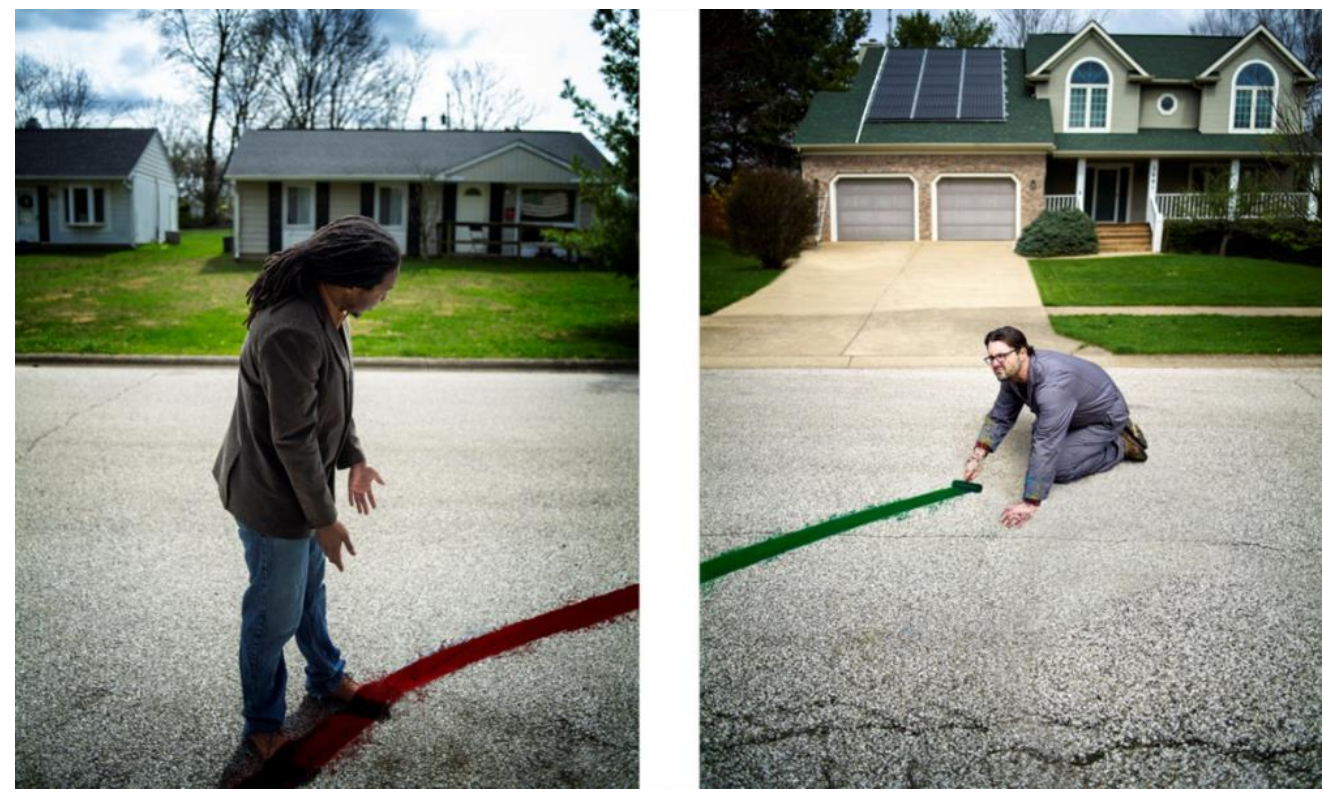

Figure 2

Address the Issue, Keep them out of my Neighborhood, 2020. Photograph.
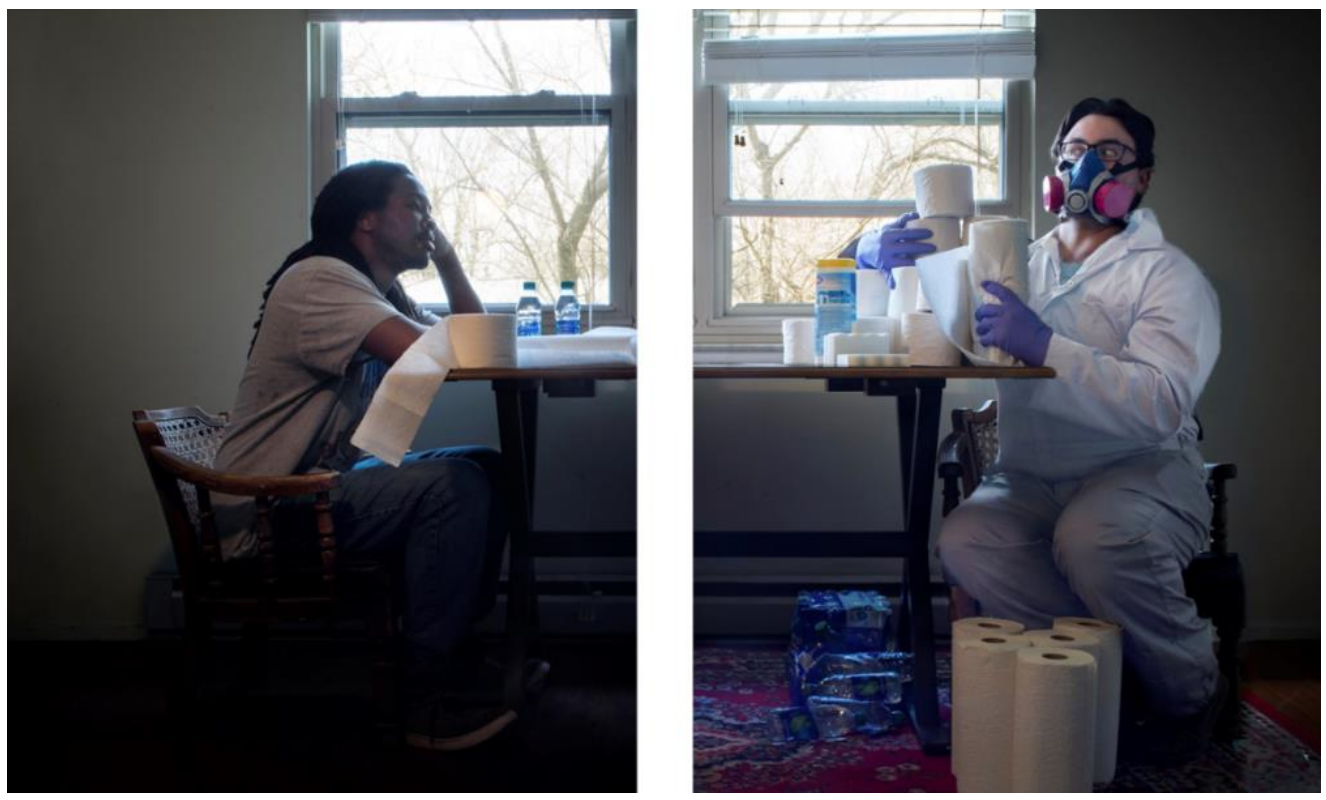

Figure 3

Address the Issue, Please Practice Racial Distancing, 2020. Photograph. 

4.0 United States License.

\section{ULIS D-Surle}

This journal is operated by the University Library System of the University of Pittsburgh as part of its D-Scribe Digital Publishing Program, and is co-sponsored by the University of Pittsburgh Press. 